\title{
Origem e distribuição do nervo toracodorsal em fetos de suínos da linhagem Pen Ar Lan
}

\author{
Eleusa Marta Mendonça Tavares \\ Juliana França Ortega* \\ Angelita das Graças de Oliveira Honorato \\ Lázaro Antônio dos Santos \\ Frederico Ozanam Carneiro e Silva
}

\author{
Faculdade de Medicina Veterinária, Universidade Federal de Uberlândia \\ Avenida Pará, 1720, Campus Umuarama, Bloco 2T, CEP 38400-902, Uberlândia - MG, Brasil \\ *Autor para correspondência \\ julianafortega@gmail.com
}

Submetido em 13/06/2011

Aceito para publicação em 17/11/2011

\section{Resumo}

Considerando a importância dos nervos que compõem o plexo braquial, objetivou-se estudar a origem e distribuição do nervo toracodorsal. Dessa forma, foram utilizados 30 fetos de suínos da linhagem Pen Ar Lan obtidos de abortos naturais em criatórios da região do Triângulo Mineiro. As peças foram preparadas por meio de injeções de soluções de Neoprene Látex " 450 ” a 50\% e de formaldeído a 10\%, na artéria aorta descendente, e imersão nessa mesma solução por um período mínimo de 48 horas. As dissecações foram realizadas bilateralmente até atingir o plexo braquial, que surgiu dos ramos espinhais ventrais do sexto (C6), sétimo (C7) e oitavo (C8) nervos cervicais e do primeiro torácico (T1). Constatou-se que o nervo toracodorsal foi formado a partir de C8 em dois antímeros (3,33\%); de T1 em 17 antímeros (28,33\%); e de C8 e T1 em 41 antímeros $(68,33)$ e que houve simetria quanto à sua origem em 23 animais $(76,66 \%)$. Verificou-se, também, que o nervo toracodorsal enviou ramos em $100 \%$ dos casos para o músculo grande dorsal e em $36,66 \%$ para o redondo maior.

Palavras-chave: Anatomia, Miologia, Plexo braquial, Suidae

\section{Abstract}

Origin and distribution of the thoracodorsal nerve in pig fetuses of the lineage Pen Ar Lan. Considering the importance of the nerves that make up the brachial plexus, the aim was to study the origin and distribution of the thoracodorsal nerve. Thus, 30 pig fetuses from the lineage Pen Ar Lan obtained from natural abortions in breedings of the Triangulo Mineiro region were used. The specimens were prepared through the injection of $50 \%$ Neoprene Latex " 450 " and $10 \%$ formaldehyde solutions in the descending aorta artery, and immersion in the same solution for least 48 hours. The dissections were carried out bilaterally until reaching the brachial plexus, that emerged from the spinal ventral branches of the sixth (C6), seventh (C7) and eighth (C8) cervical nerves and from the first thoracic (T1). It was found that the thoracodorsal nerve was formed from C8 in two antimeres (3.33\%); fromT1 in 17 antimeres (28.33\%); and from C8 and T1 in 41 antimeres (68.33) and that there was symmetry with regard to its origin in 23 animals $(76.66 \%)$. It was also found that the thoracodorsal nerve sent branches in $100 \%$ of cases for the latissimus dorsi muscle, and $36.66 \%$ for the teres major.

Key words: Anatomy, Brachial plexus, Miology, Suidae 


\section{Introdução}

Os primeiros suínos no Brasil foram trazidos por Martin Afonso de Souza em 1532 e pertenciam às raças existentes na Península Ibérica que, com o passar dos séculos, deram origem às raças nacionais, chamadas caipiras, exploradas como criação de subsistência até meados do século XX. A partir daí, a necessidade de uma maior produção para atender $\mathrm{o}$ crescente aumento populacional urbano e a mudança do hábito do consumo de banha para o de óleos vegetais estimulou empreendedores a introduzir a suinocultura comercial com a importação de raças exóticas. Mais tarde, em 1970, iniciou-se o melhoramento genético dos suínos e hoje estão instaladas no Brasil dez empresas de melhoramento genético, entre estas a Pen Ar Lan (FÁVERO; FIGUEIREDO, 2009).

A linhagem Pen Ar Lan é resultante do cruzamento entre o cachaço P76 e a matriz Naïma. O cachaço P76 foi criado a partir das raças Duroc, Hampshire, Pietrain e Large White e selecionado sob critérios de crescimento, conversão alimentar, produção de carne magra e livre dos genes halotano (do estresse) e RN - (das carnes ácidas). A matriz Naïma combina características de qualidade de carcaça e crescimento das raças europeias (Large White e Landrace) e de prolificidade das raças chinesas (Meishan e Xia Jing) (PEN AR LAN, 2009).

Em suínos, o plexo braquial é formado pelos ramos ventrais do quinto (C5), sexto (C6), sétimo (C7) e oitavo (C8) nervos cervicais e pelo primeiro (T1) nervo torácico (SCHWARZE; SCHRODER, 1970; BERG, 1978; GHOSHAL, 1986c). O segmento inicial do plexo braquial, de acordo com Konig et al. (2004), surge junto ao músculo escaleno, na região axilar, para em seguida distribuir-se na musculatura do membro torácico, do cinturão escapular e da lateral do tórax e também para a pele da mesma região. Os ramos periféricos que compõem o plexo braquial na espécie suína, relacionados por Ghoshal (1986c), são o nervo supra-escapular, os subescapulares, os peitorais, o musculocutâneo, o axilar, o radial, o ulnar, o mediano, o torácico longo, o toracodorsal, e o torácico lateral.

Ghoshal (1986a;1986b;1986c) estudou diferentes espécies e observou que em suínos e bovinos o nervo toracodorsal é formado pelos ramos ventrais do sétimo e do oitavo componentes cervicais do plexo braquial e em equinos e caprinos, origina-se somente do ramo ventral do oitavo componente cervical. Ele inerva o músculo grande dorsal e, às vezes, fornece ramificações colaterais para o músculo redondo maior.

A anatomorfologia veterinária ao estudar a forma, topografia e estrutura dos tecidos e órgãos que compõem os corpos dos animais, constitui-se em instrumento fundamental para outras áreas da medicina veterinária como a clínica, a cirurgia, a produção, a reprodução e a genética. Assim, a anatomia dos suínos tem sido objeto de investigação dos pesquisadores envolvidos na busca de informações mais precisas sobre os aspectos anatomofisiológicos destes animais, bem como daqueles interessados na preservação de uma determinada raça ou melhoramento de uma linhagem.

Considerando a importância dos nervos que compõem o plexo braquial, por suprirem quase todas as estruturas do membro torácico (DYCE et al., 2004), objetivou-se estudar a origem e distribuição do nervo toracodorsal em fetos de suínos da linhagem Pen Ar Lan.

\section{Material e Métodos}

Foram utilizados 30 fetos de suínos da linhagem Pen Ar Lan, com aproximadamente três meses de gestação, obtidos de abortos naturais em criatórios da região do Triângulo Mineiro, onde foram conservados em congeladores até serem conduzidos ao Laboratório de Anatomia Veterinária da Universidade Federal de Uberlândia, Minas Gerais, para seu descongelamento e posterior preparação para a sua dissecação.

Assim, a artéria aorta descendente, parte torácica, foi individualizada e canulada por meio de uma incisão vertical no nível do nono espaço intercostal do antímero esquerdo e através dela injetada solução marcadora de vasos sanguíneos, Neoprene Látex "450” a 50\% (Du Pont do Brasil - Indústrias Químicas), corada com pigmento específico (Globo S. Tintas e Pigmentos) e solução de formaldeído a 10\%. Em seguida, os fetos permaneceram mergulhados nesta mesma solução por um período mínimo de $48 \mathrm{~h}$. 
As dissecações foram realizadas bilateralmente, através de incisões que partiram da pele, próximo ao osso esterno, até atingir o plexo braquial e, quando necessário, utilizou-se uma lupa com aumento de 10x para facilitar a visualização dos ramos.

A documentação dos resultados foi realizada a partir de fotografias das origens e distribuições do nervo toracodorsal. A nomenclatura adotada para a descrição dos resultados esteve de acordo com o International Committee On Veterinary Gross Anatomical Nomenclature (2005).

Os dados obtidos foram analisados de forma descritiva em termos de porcentagem simples.

\section{Resultados}

Nos 30 fetos de suínos da linhagem Pen Ar Lan, verificou-se que o plexo braquial, em 100\% dos casos, surgiu de ligações estabelecidas entre o sexto (C6), sétimo (C7) e oitavo (C8) ramos ventrais dos nervos espinhais cervicais e primeiro torácico (T1) (Figura 1) e que o nervo toracodorsal originou-se de $\mathrm{C} 8 \mathrm{em}$ dois antímeros $(3,33 \%)$, um exemplar à direita $(1,66 \%)$ e outro à esquerda (1,66\%); de T1 (Figura 2) em 17 antímeros $(28,33 \%)$, nove casos à direita $(15 \%)$ e oito à esquerda (13,33\%); e de C8 e T1, em 41 antímeros $(68,33 \%), 20$ à direita $(33,33 \%)$ e 21 à esquerda (35\%).

Observou-se que a origem mais comum do referido nervo foi em C8 e T1 (Figura 3).

As origens do nervo toracodorsal nos ramos ventrais dos nervos espinhais, em ambos antímeros, estão representadas na Tabela 1.

O nervo toracodorsal apresentou simetria, quanto à sua origem, em 23 animais (76,66\%). Somente com origem em C8, um animal (3,33\%); em T1, cinco animais (16,66\%); e em C8 e T1, 17 animais (56,66\%).

FIGURA 1: Fotografia da face medial do membro torácico de feto de suíno Pen Ar Lan onde o plexo braquial emergiu de C6 (1), C7 (2), C8 (3) e T1 (4).

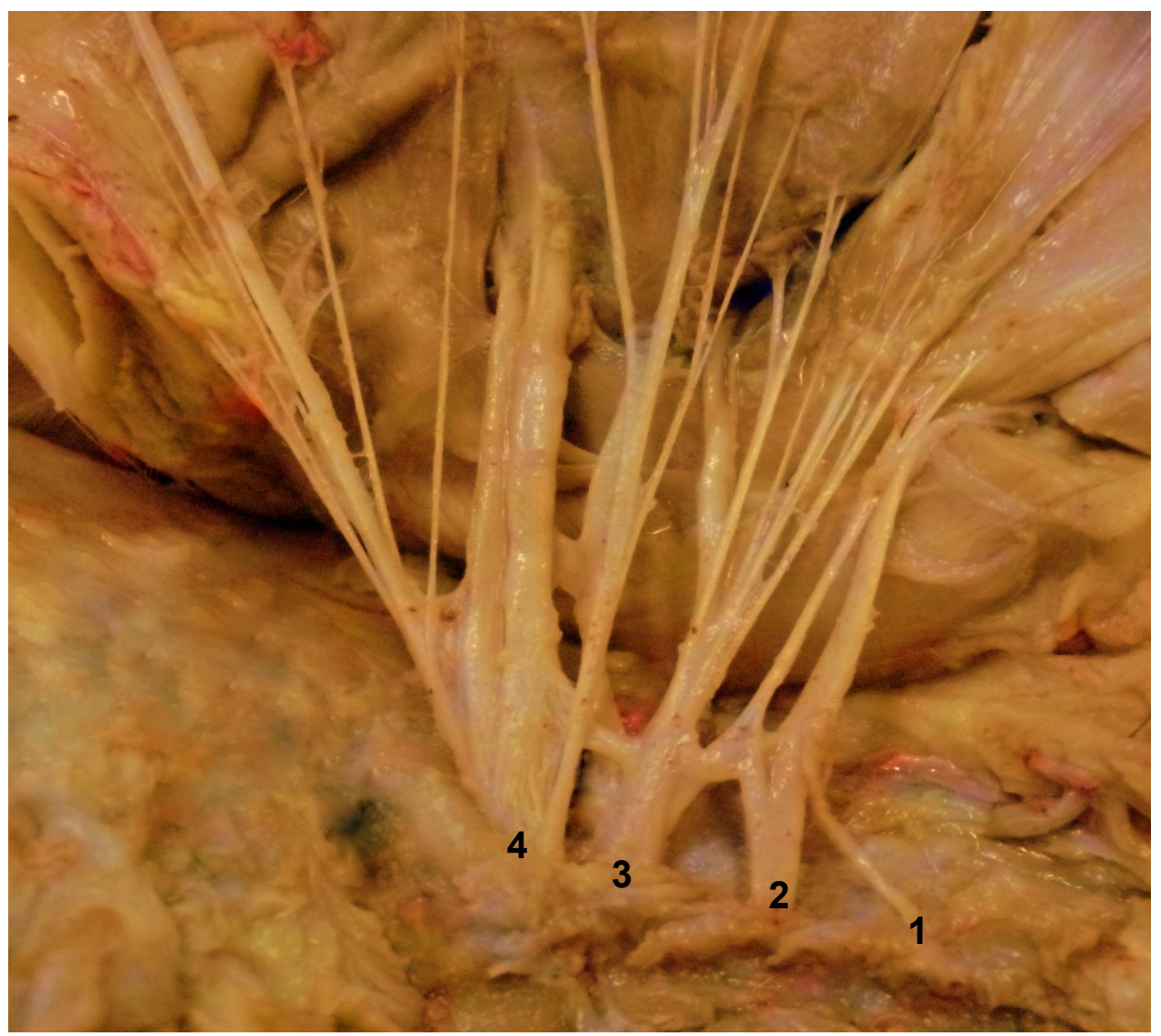


FIGURA 2: Fotografia da face medial do membro torácico de feto de suíno Pen Ar Lan onde o nervo toracodorsal (A) originou-se de T1 (1).

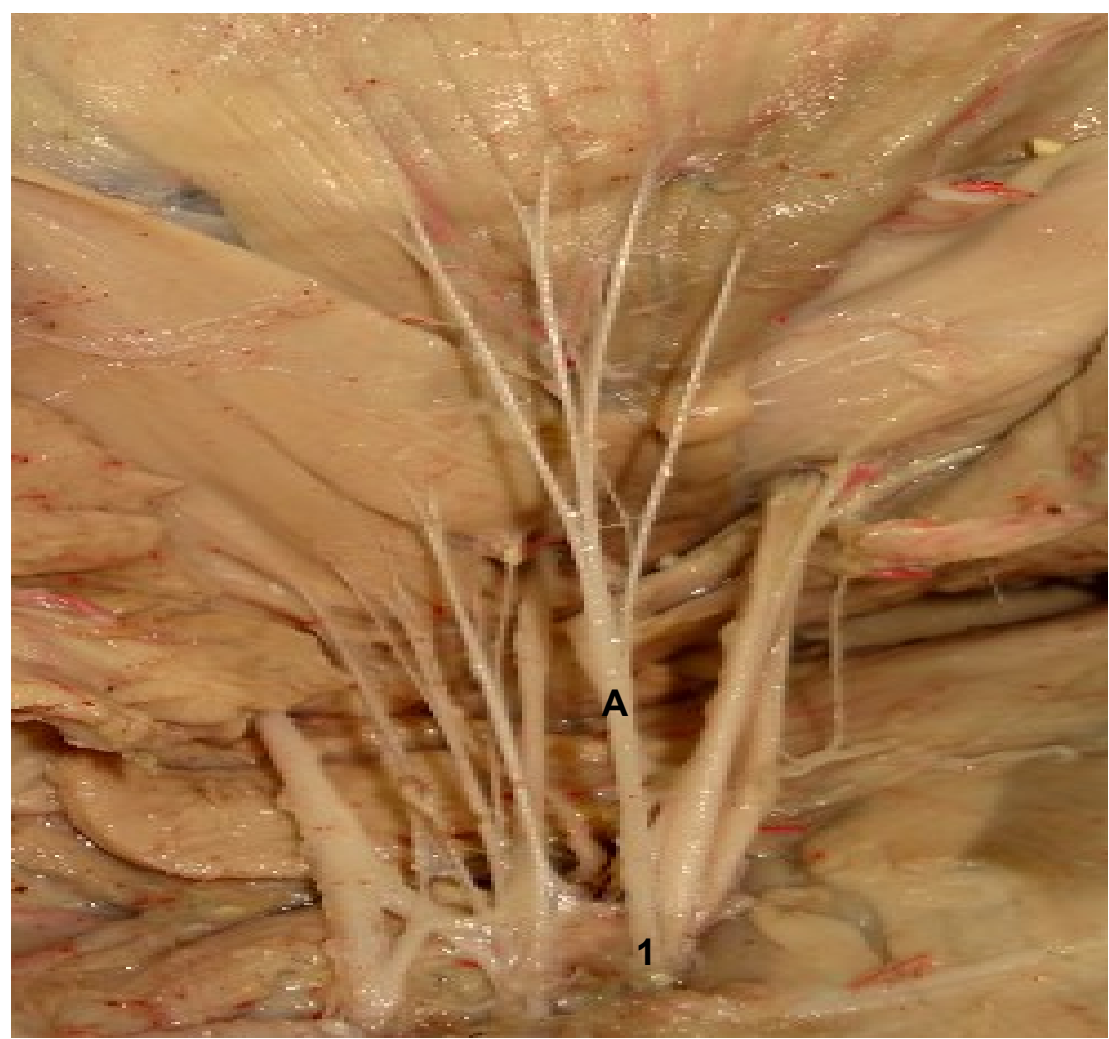

FIGURA 3: Fotografia da face medial do membro torácico de feto de suíno Pen Ar Lan onde o nervo toracodorsal (A) originou-se de C8 (1) e T1 (2).

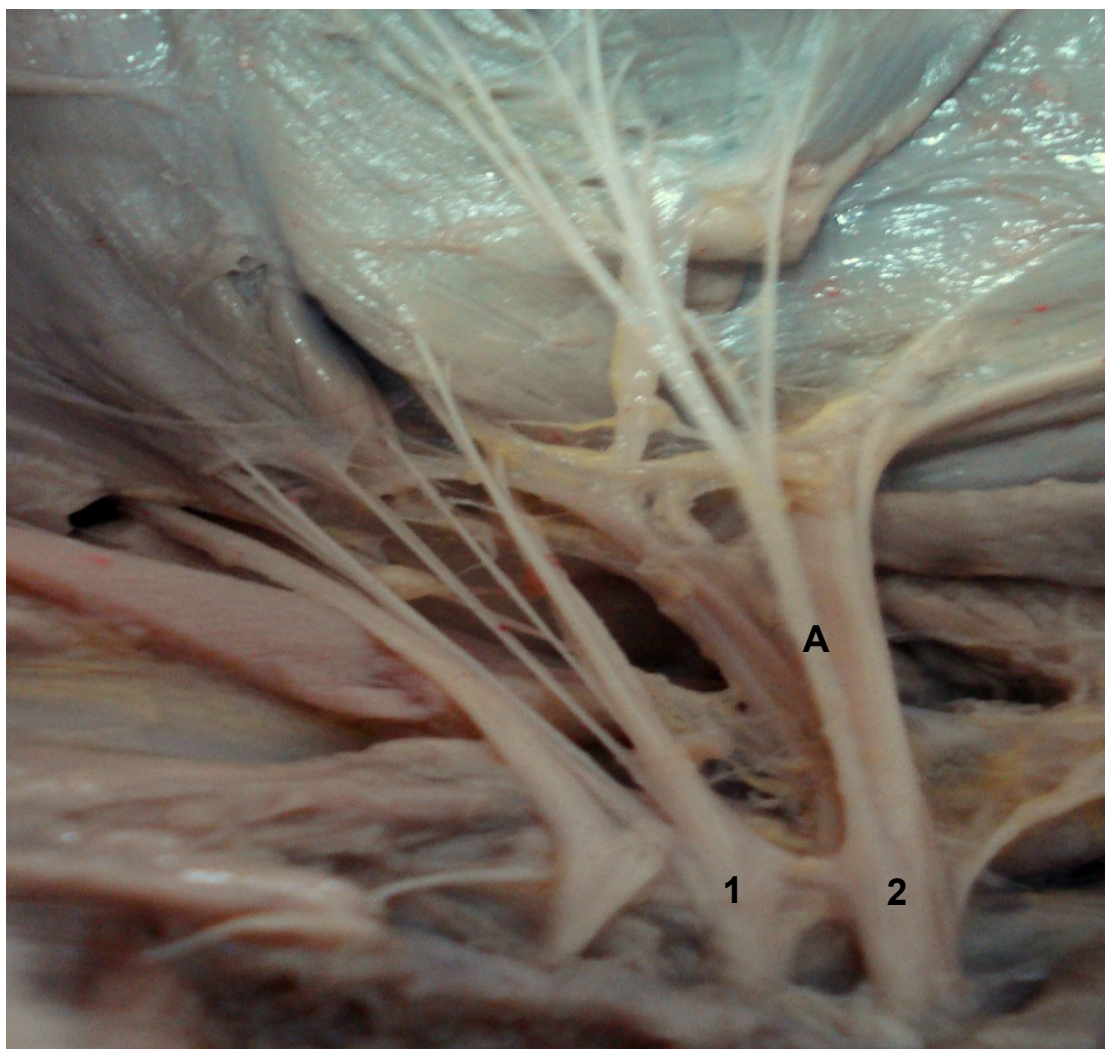


TABELA 1: Origens do nervo toracodorsal (\%) nos ramos ventrais dos nervos espinhais em fetos de suínos da linhagem Pen Ar Lan nos antímeros direito $(\mathrm{AD})$ e esquerdo (AE). UberlândiaMG. 2011.

\begin{tabular}{ccc|}
\hline RAMOS & \multicolumn{2}{c|}{ FREQUÊNCIA } \\
\cline { 2 - 3 } VENTRAIS & AD & AE \\
\hline $\mathrm{C} 8$ & $1,66 \%$ & $1,66 \%$ \\
\hline $\mathrm{T} 1$ & $15 \%$ & $13,33 \%$ \\
\hline $\mathrm{C} 8+\mathrm{T} 1$ & $33,33 \%$ & $35 \%$ \\
\hline
\end{tabular}

Quanto à sua distribuição, constatou-se que, ao longo de seu trajeto, este nervo enviou ramos musculares em $100 \%$ dos antímeros para o grande dorsal e em $36,66 \%$ para redondo maior, sendo sete à direita $(11,66 \%)$ e 15 à esquerda (25\%) (Figura 4).

O nervo toracodorsal, em ambos antímeros, cedeu de quatro a nove ramos para o músculo grande dorsal e de um a dois para o redondo maior (Tabela 2).
TABELA 2: Ramificações musculares do nervo toracodorsal em fetos de suínos da linhagem Pen Ar Lan nos antímeros direito (AD) e esquerdo (AE). Uberlândia-MG. 2011.

\begin{tabular}{ccc} 
MÚSCULOS & $\begin{array}{c}\text { AD: № de } \\
\text { RAMOS } \\
\text { (\% de animais) }\end{array}$ & $\begin{array}{c}\text { AD: № de } \\
\text { RAMOS } \\
\text { (\% de animais) }\end{array}$ \\
& $4(3,33 \%)$ & $4(10 \%)$ \\
Grande dorsal & $5(10 \%)$ & $5(3,33 \%)$ \\
& $6(40 \%)$ & $6(0 \%)$ \\
& $7(23,33 \%)$ & $7(26,66 \%)$ \\
& $8(3,33 \%)$ & $8(46,66 \%)$ \\
Redondo maior & $9(20 \%)$ & $9(13,33 \%)$ \\
\hline & $0(76,66 \%)$ & $0(50 \%)$ \\
& $1(20 \%)$ & $1(30 \%)$ \\
\hline
\end{tabular}

Todos os dados encontrados quanto à origem e distribuição do nervo toracodorsal foram analisados de forma descritiva em termos de porcentagem simples.

FIGURA 4: Fotografia da face medial do membro torácico de feto de suíno Pen Ar Lan onde o nervo toracodorsal (1) emitiu ramos para os músculos grande dorsal (A) e redondo maior (B).

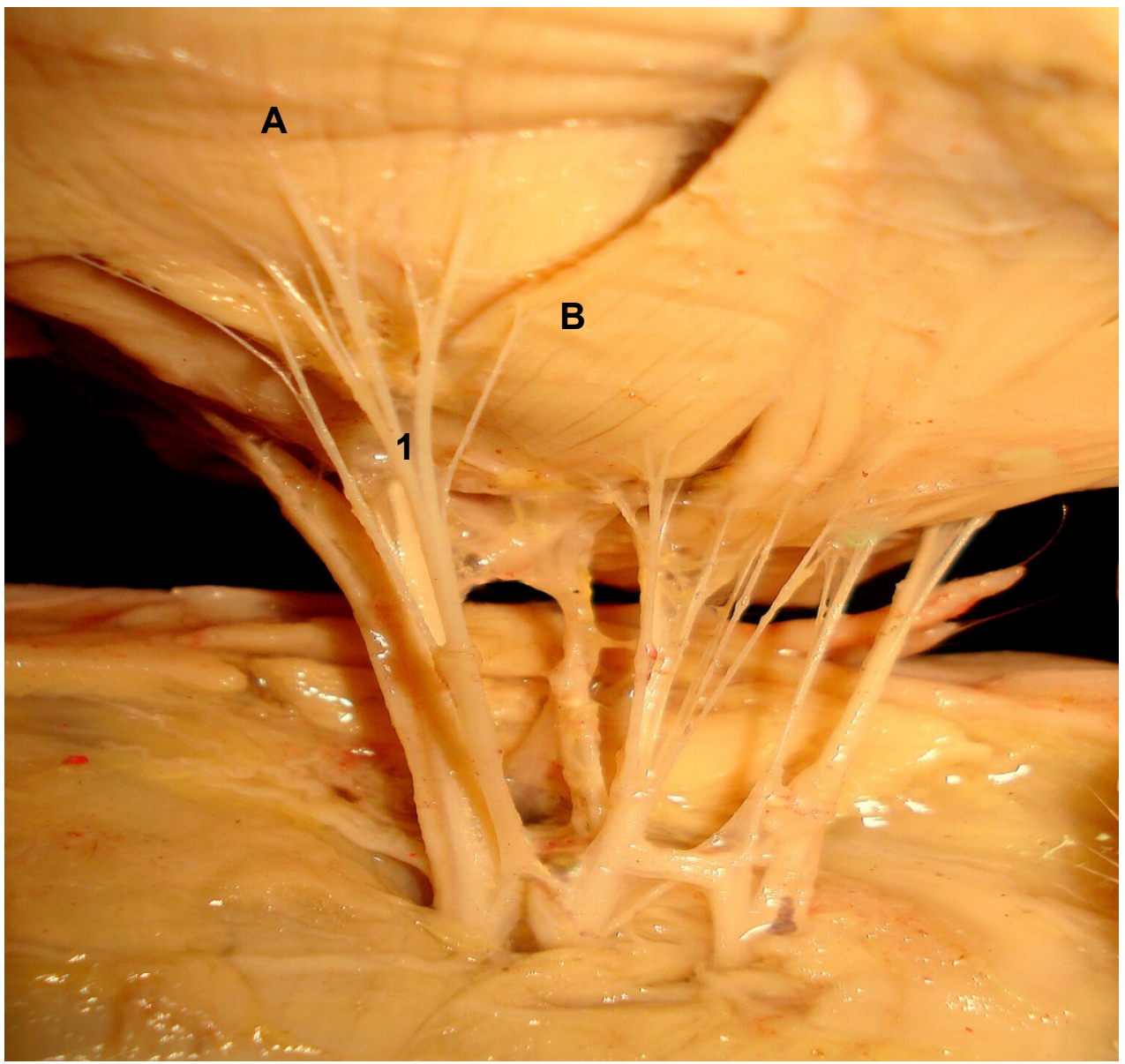




\section{Discussão}

O plexo braquial em fetos de suínos da linhagem Pen Ar Lan surgiu de ligações estabelecidas entre o sexto (C6), sétimo (C7) e oitavo (C8) ramos ventrais dos nervos espinhais cervicais e primeiro torácico (T1) e o nervo toracodorsal foi observado como um dos seus ramos. Contudo, Schwarze e Schroder (1970), Berg (1978), Ghoshal (1986c), afirmam que C5 também participa da formação do plexo braquial nos suínos e o nervo toracodorsal está entre os ramos periféricos que o compõem.

Ghoshal (1986b; 1986c) relata que o nervo toracodorsal deriva suas fibras de C7 e C8 no suíno e que no bovino, apesar de ocasionalmente emergir de $\mathrm{C} 8$ e T1, essencialmente é de $\mathrm{C} 7$ e C8 que se origina. $\mathrm{Na}$ presente pesquisa, em nenhum dos animais analisados foi observada a presença de $\mathrm{C} 7$ na formação do referido nervo.

Evans e Delahunta (2001), em cães, Ghoshal (1986a;1986b), em equinos e caprinos e Gamba et al. (2007), em chinchilas, afirmaram que o nervo toracodorsal origina-se do oitavo nervo cervical. Os resultados obtidos neste trabalho demonstram que esse nervo originou-se, somente de C8, em dois antímeros dos animais estudados.

De acordo com Godinho et al. (1975), para caprino e ovino, Santos et al. (2010), para fetos de bovinos azebuados e Teixeira et al. (2002), para cervos do pantanal, o nervo toracodorsal é constituído por fibras de C8 e T1. Situação encontrada em $68,33 \%$ dos antímeros dos suínos estudados, sendo, portanto, a contribuição mais importante para a formação do nervo pesquisado.

Godinho et al (1975), em bovinos, e Scavone et al. (2008), em pacas, destacam que o segundo nervo torácico também participa da formação do toracodorsal. A origem em T2 não foi identificada nos animais desta investigação.

Moura et al. (2007) observaram que, em catetos, o nervo toracodorsal origina-se de fibras dos ramos ventrais do sexto, sétimo e oitavo nervos espinhais cervicais, em ambos antímeros de todos animais estudados. Contudo, em fetos de suínos Pen Ar Lan não foi encontrado nenhum caso em que ocorresse a participação de C6 e C7.

Moura et al. (2007), em catetos, e Scavone et al. (2008), em pacas, afirmaram que o nervo toracodorsal apresenta simetria em relação à sua origem. Neste trabalho esta ocorrência apresentou-se em 23 animais $(76,66 \%)$.

Quanto à distribuição do nervo toracodorsal para o músculo grande dorsal, em 100\% dos casos evidenciouse neste estudo a concordância com os informes de Ghoshal (1986a; 1986b; 1986c; 1986d) em suínos, equinos, bovinos, ovinos, caprinos e cães; Godinho et al. (1975), em caprinos, ovinos e bovinos; Santos et al. (2010), em fetos de bovinos azebuados; Evans e Delahunta (2001), em cães; Sisson e Grossman (1975), em equinos; Schwarze e Schroder (1970), Nickel et al. (1986) e Frandson (1979), nos animais domésticos; Scavone et al. (2008), em pacas; e Gamba et al. (2007), em chinchilas.

Quanto à emissão de ramos para o músculo redondo maior, os achados desta pesquisa, em que foram encontradas 22 ocorrências, estão de acordo com os relatos de Ghoshal (1986b; 1986c) em ovinos e suínos; Godinho et al (1975) em caprinos, ovinos e bovinos; e Santos et al. (2010) em fetos de bovinos azebuados, em que também aparecem casos de distribuição neste músculo.

A inervação do músculo peitoral profundo, relatada por Ghoshal (1986b) em ovinos e por Godinho et al. (1975) em bovinos, não foi identificada nos animais da atual investigação.

Do exposto, nota-se que as poucas diferenças encontradas entre os dados obtidos no presente estudo e a literatura consultada são relativas à origem do nervo toracodorsal também em $\mathrm{C} 7$ e $\mathrm{T} 2$ e as raras ocorrências de sua distribuição no músculo peitoral profundo. Contudo, a concordância entre os achados desta pesquisa e os relatos dos autores quanto à origem em $\mathrm{C} 8$ e distribuição no músculo redondo maior foi em $100 \%$ dos casos.

De acordo com os resultados foi possível concluir que o nervo toracodorsal em fetos de suínos da linhagem Pen Ar Lan originou-se dos ramos espinhais ventrais de 
C8, T1 e C8 e T1, com predominância da origem em C8 e T1, e distribuíram-se nos músculos grande dorsal e redondo maior.

\section{Referências}

BERG, R. Regiones del miembro torácico. In: BERG, R. (Ed.). Anatomia topográfica e aplicada de los animales domésticos. Cap. 7. Madrid: Editorial AC, 1978. p. 295-346.

DYCE, K. M.; SACK, W. O.; WENSING, C. J. G. Tratado de anatomia veterinária. 3. ed. Rio de Janeiro: Elsevier, 2004. 872 p.

EVANS, H. E.; DELAHUNTA, A. Pescoço, tórax e membro torácico. In: EVANS, H. E.; DELAHUNTA, A. (Ed.). Guia para a dissecação do cão. 5 ed. Rio de Janeiro: Guanabara Koogan, 2001. p. 67-99.

FÁVERO, J. A.; FIGUEIREDO, E. A. P. Evolução do melhoramento genético de suínos no Brasil. Revista Ceres, Concórdia, v. 56, n. 4, p. 420-427, 2009. Disponível em: <http://www.ceres.ufv.br/ CERES/revistas/V56N004_00609.pdf>.

FRANDSON, R. D. Anatomia e fisiologia dos animais domésticos. 2. ed. Rio de Janeiro: Guanabara Koogan, 1979. 430 p.

GAMBA, C. O.; CASTRO, T. F.; RICKES, E. M.; PEREIRA, M. A. M. Sistematização dos territórios nervosos do plexo braquial em chinchila (Chinchilla lanigera). Brazilian Journal of Veterinary Research and Animal Science, São Paulo, v. 44, n. 4, p. 283-289, 2007.

GHOSHAL, N. G. Nervos espinhais. In: GETTY, R. (Ed.). Sisson/ Grossman anatomia dos animais domésticos. v. 1. 5. ed. Rio de Janeiro: Guanabara Koogan, 1986a. p. 620-641.

GHOSHAL, N. G. Nervos espinhais. In: GETTY, R. (Ed.). Sisson/ Grossman anatomia dos animais domésticos. v. 1. 5. ed. Rio de Janeiro: Guanabara Koogan, 1986b. p. 1052-1077.

GHOSHAL, N. G. Nervos espinhais. In: GETTY, R. Sisson/ Grossman anatomia dos animais domésticos. v. 2. 5. ed. Rio de Janeiro: Guanabara Koogan, 1986c. p. 1294-1307.

GHOSHAL, N. G. Nervos espinhais. In: GETTY, R. Sisson/ Grossman anatomia dos animais domésticos. v. 2. 5. ed. Rio de Janeiro: Guanabara Koogan, 1986d. . 1595-1617.

GODINHO, H. P.; CARDOSO, F. M.; NASCIMENTO, J. F. Anatomia dos ruminantes domésticos. Belo Horizonte: Universidade Federal de Minas Gerais, 1975. 319 p.
INTERNATIONAL COMMITTEE ON VETERINARY GROSS ANATOMICAL NOMENCLATURE. Nomina anatomica veterinaria. 5. ed. Hannover: Editorial Committee, 2005. 166 p.

KONIG, H. E.; LIEBICH, H. G.; CERVENY, C. Sistema Nervoso. In: KONIG, H. E.; LIEBICH, H. (Ed.). Órgãos e sistemas. v. 2, Cap. 14. Porto Alegre: Artmed, 2004. p. 203-275.

MOURA, C. E. B.; ALBUQUERQUE, J. F. G.; MAGALHÃES, M. S.; SILVA, N. B.; OLIVEIRA, M. F.; PAPA, P. C. Análise comparativa da origem do plexo braquial de catetos (Tayassu tajacu). Pesquisa Veterinária Brasileira, Seropédica, v. 27, n. 9, p. 357-362, 2007.

NICKEL, R.; SCHUMMER, A.; SEIFERLE, E.; FREWEIN, J.; WILKENS, H.; WILLE, K. H. Muscles of the limbs. In: NICKEL, R.; SCHUMMER, A.; SEIFERLE, E.; FREWEIN, J.; WILKENS, H.; WILLE, K. H. (Ed.). The locomotor system of the domestic mammals. v. 1. Berlim: Paul Parey, 1986. p. 324-394.

PEN AR LAN. Escolha a genética do futuro. 2009. Disponível em: <http://www.penarlan.com.br/2010/index.php?link=ver_notici a\&id=13\&conteudo=noticias $>$. Acesso em: 6 mar. 2011.

SANTOS, L. A. DOS; SILVA, F. O. C.; GUIMARÃES, E. C.; EURIDES, D.; LIZARDO, F. B.; SOUSA, G. C.; NETO, M. A. F.; CABRAL, L. G.; SANTOS, V. M. Origem e distribuição do nervo toracodorsal em fetos de bovinos azebuados. Bioscience Journal, Uberlândia, v. 26, n. 6, p. 948-955, 2010.

SCAVONE, A. R. F.; MACHADO, M. R. F.; GUIMARÃES, G. C.; OLIVEIRA, F. S.; GERBASI, S. H. B. Análise da origem e distribuição dos nervos periféricos do plexo braquial da paca (Agouti paca, LINNAEUS, 1766). Ciência Animal Brasileira, Goiânia, v. 9, n. 4, p. 1046-1055, 2008.

SCHWARZE, E.; SCHRODER, L. Nervios espinales. In: SCHWARZE, E.; SCHRODER, L. (Ed.). Compêndio de anatomia veterinária: sistema nervioso y órganos de los sentidos. v. 4. Zaragoza: Acríbia, 1970. p. 61-90.

SISSON, S.; GROSSMAN, J. D. Neurologia. In: SISSON, S.; GROSSMAN, J. D. (Ed.). Anatomia de los animales domésticos. 4. ed. Barcelona: Salvat, 1975. p. 758-855.

TEIXEIRA, D. G.; OLIVEIRA, M. F.; MIGLINO, M. A.; PASSIPIERI, M.; MOURA, C. E. B.; COSTA, W. P. Origem dos nervos derivados do plexo braquial de cervos do pantanal (Mazana sp.). International Journal of Morphology, Temuco, v. 21, n. 1, p. 85, 2003. Disponível em: <http://www.biblioanatomica. com.ar/XXXIX\%20Congreso \%20 Argentino $\% 20 \mathrm{de} \% 20$ Anatom $\%$ C3\%ADa $\% 20-\% 20 \% 202002$.pdf $>$. 